\title{
"IMAGENS SONORAS DO AMBIENTE: EDUCAÇÃO AMBIENTAL E ENSINO DE MÚSICA - RELATO DE UMA PESQUISA PARTICIPANTE NO ENSINO SUPERIOR DE LICENCIATURA EM MÚSICA"1
}

\author{
Marco Aurélio A. da Silva \\ maureliosilva@ig.com.br
}

\begin{abstract}
Esta pesquisa tem o objetivo de analisar a prática docente na licenciatura em música, com a finalidade de auxiliar a ação educativa acerca do ambiente sonoro e suas implicações na sociedade. Tem como aporte teórico o trabalho de R. Murray Schafer, que desenvolveu um projeto chamado a Paisagem Sonora Mundial, realizando um estudo sistematizado sobre a produção sonora em ambientes rurais e urbanos. Buscou-se um elo entre o saber e a ação através da pesquisa participante, tendo os alunos e o professor do Curso Superior de Licenciatura em Música como sujeitos. Investigou-se e construiu-se conceitos de paisagem sonora, música, ambiente, som, ruído, poluição sonora. Concluí-se que a música pode auxiliar criticamente à construção de uma consciência ecológica na busca da acuidade sonora e do vínculo que pode ser estabelecido entre a educação ambiental e a educação musical. Ao fim do processo evidencia-se que é responsabilidade do educador musical a construção desta acuidade chamada audição inteligente.
\end{abstract}

Palavras-chave: Ensino de Música; Ensino e Ambiente; Paisagem Sonora; Audição inteligente.

\begin{abstract}
This research aims to analyse the teaching practice on the Music Education Course, looking for the goal of helping out the education practice about its sound atmosphere and its connotations in a society. It is based on the theories from R. Murray Schafer who developed a work called World Sound Picture in which he studyed the production of the sound in rural and urban surroundings. It was seeked a lace between the knowledge and the practice throughout a participant research having the students and the teacher from the Music Education Course as the subjects. It was investigated and it was built the concepts of sound picture, music, environments, sound, noise, sound pollution. This research proves that the music can help, critically, to build of an ecologic conscience when looking for a sound accuracy and for a lace between the environmental and musical educations. At last this research can show that the music teacher is responsible for the construction of this accuracy which is called smart hearing.
\end{abstract}

Keywords: Music Education; Education and Environment; Sound Picture; Smart Hearing.

\section{INTRODUÇÃO}

O objeto desta pesquisa é analisar o vínculo que pode ser estabelecido entre a educação ambiental e a educação musical. A música está ligada ao seu tempo e à sociedade, ou seja, ao contexto histórico-social e é tarefa quase impossível dissociar a produção artístico-musical de seu ambiente social onde ela é influenciadora e influenciada. Hoje a preservação ambiental ganhou espaço e consiste em sério problema

${ }^{1}$ Este trabalho é oriundo da Dissertação "IMAGENS SONORAS DO AMBIENTE E EDUCAÇÃO RELATO DE UMA PESQUISA PARTICIPANTE NO ENSINO SUPERIOR DE LICENCIATURA EM MÚSICA”, defendida no Curso de Mestrado Profissional em Ensino de Ciências da Saúde e do Ambiente/UNIPLI. 
a questão da nova paisagem sonora a qual estamos expostos.

A educação ambiental pode ser trabalhada em diversos contextos e níveis de entendimento, pois, não é uma disciplina isolada do contexto histórico social e atinge diretamente a todos. A música, então, se configura em importante ferramenta para o desenvolvimento de uma audição sensível, contribuindo assim, para a construção de um ambiente sonoro mais equilibrado. "A educação ambiental deve orientar-se para a comunidade. Deve procurar incentivar o indivíduo a participar ativamente da resolução dos problemas no seu contexto de realidades específicas" (REIGOTA, 2001, p. 12).

A educação musical e a educação ambiental têm a paisagem sonora como elo. Assim, questões relacionadas à poluição sonora perpassam estes dois universos educacionais em constante tangência. $O$ desenvolvimento de uma audição mais cuidadosa, não somente musical, mas de todo ambiente, inclusive onde a arte da música se processa, se configura a base de investigação desta pesquisa.

Não vemos a música como saída redentora, porém, nossa hipótese é de que a música pode auxiliar na tomada de uma consciência ecológica educativa acerca da paisagem sonora atual e seus efeitos sobre o ambiente. Com um olhar interdisciplinar podemos investigar a poluição sonora através da música buscando uma interface entre educação musical e educação ambiental. Construindo uma audição consciente estaremos diretamente influindo sobre a produção sonora da sociedade. O objetivo desta pesquisa foi, portanto, analisar a prática docente na licenciatura de música com a finalidade de auxiliar a ação educativa acerca do ambiente sonoro.

\section{DISCUSSÃO TEÓRICA}

Ainda hoje, é muito comum a associação do termo meio ambiente com espaços rurais ou simplesmente imagens ligadas à fauna e à flora. Com toda certeza estas imagens fazem parte do ambiente, porém não estão sós. Nosso ambiente é formado por todos os elementos que nele estão contidos - agradáveis ou não - e nós fazemos parte dele. Por exemplo: O trânsito das metrópoles é parte integrante do ambiente destas cidades.

Segundo Reigota (2001), meio ambiente é:

Um lugar determinado e ou percebido onde estão em relações dinâmicas e em constante interação os aspectos naturais e sociais. Essas relações acarretam processos de criação cultural e tecnológica e processos históricos e políticos de transformação da natureza e da sociedade (p. 21). 
É necessário que a sociedade tenha consciência das transformações e crie mecanismos que possibilitem uma convivência ecologicamente possível, ou seja, transformar sem negligenciar a qualidade de vida. Pouco, ainda, atentamos para as questões ambientais ligadas à acuidade sonora, sendo assim, vemos na educação ambiental uma forma de promover ações que visem estabelecer uma relação ecologicamente possível entre o homem e o ambiente, buscando mecanismos que garantam sua sobrevivência, o equilíbrio deste ambiente e a qualidade de vida. "Os recursos didáticos mais artísticos e criativos são os mais adequados à perspectiva inovadora da educação ambiental” diz Reigota (2001, p. 49). Assim, a educação musical pode através da construção de uma audição inteligente, levar a sociedade a uma consciência acerca de como a poluição sonora tem tomado conta do ambiente cotidiano e de seus efeitos sobre a qualidade de vida da população.

Como nosso tema trata de imagens sonoras, vamos nos ater, aos elementos que compõem a paisagem sonora do nosso ambiente atual.

Paisagem Sonora é uma expressão usada nos países latinos, traduzida do inglês "soundscape" - neologismo criado por Schafer -, que tenta descrever, como que através de uma pintura, os sons de um determinado ambiente. Para Schafer, "paisagem sonora é todo campo de estudo acústico" (2001, p. 23) e o mundo é uma macro-composição sonora onde cada ambiente soa como um movimento musical independente. Os ambientes se diferem; uns são mais quentes que outros; mais iluminados, mais harmoniosos, mais silenciosos ou barulhentos; sendo assim, se fotografássemos estes diferentes ambientes teríamos retratos distintos de cada um deles. Com a paisagem sonora ocorre o mesmo. Ambientes diferentes nos remetem a paisagens sonoras também diferentes.

Toda paisagem sonora possui recortes, ou seja, elementos distintos que a compõe. Chamamos estes recortes de imagens sonoras, que são acontecimentos auditivos que formam a paisagem sonora ambiental, nos remetendo a visões pictóricas e a sinais visuais. Usamos o termo imagem sonora como toda informação sonoroambiental que compõe a paisagem e toda informação sonora que é acrescida ao ambiente, torna-se, naquele momento, parte integrante da paisagem sonora; descrevê-las é como olhar a nossa volta e traduzir os sons que ouvimos. Esta tradução pode ser feita de várias formas, dentre elas de forma verbal ou gráfica; a escrita musical se configura numa forma de representação gráfica que através de sinais e códigos pode prescrever ou 
descrever $^{2}$ visões sonoras. Podemos descrever em sinais musicais, por exemplo, a estrutura rítmica do termo "imagens sonoras".

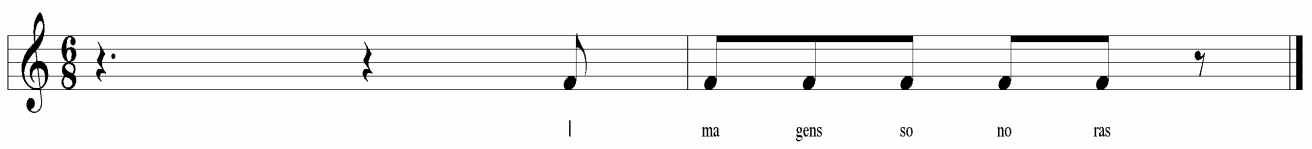

O mundo todo tem se ocupado com pesquisas e elaboração de leis que procuram manter o equilíbrio e qualidade de suas paisagens sonoras. A exemplo de Madrid, na Espanha, que criou em 2001, uma cartilha denominada "Ruído y calidad de vida", o Rio de Janeiro publicou, "Escuta! A paisagem sonora da cidade" , uma publicação educativa elaborada por músicos e pesquisadores e destinada a alunos, professores e a sociedade em geral. O Conselho Nacional de meio ambiente (NEVES e TOSTES, 1998) criou a resolução $\mathrm{n}^{\circ}$. 001 de 08 de março de 1990, (CONAMA) seção I, p. 6.408 - que estabelece os níveis e padrões aceitáveis para emissão de ruídos, porém, pouco tem sido feito em relação à fiscalização e aplicação de punições aos que desrespeitam a lei. Música e sociedade formam um duo indissociável. E para tratar deste assunto, é preciso situar-nos em torno do que pensamos ser música, tentando estabelecer um ponto em comum de raciocínio traçando a partir daí, um paralelo entre a música do passado, a música de hoje, sua influência na sociedade e vice-versa.

A educação musical não deve ser pensada de forma desarticulada ao ambiente social. A questão da poluição sonora perpassa pela falta de cuidado e atenção à percepção sonora. Neste sentido, o educador musical se torna uma peça chave na construção de uma audição cuidadosa e atenta voltada para a qualidade dos sons e preocupada com o ambiente sonoro atual e futuro, pois, através da música a educação pode despertar uma consciência responsável acerca do ambiente sônico. Se quisermos ouvir sons de pássaros teremos que diminuir os sons de máquinas dos centros urbanos e a música pode nos dar a sensibilidade necessária para esta audição mais atenta, que enquanto objeto de estudo, deve ser articulada, de forma transversal, com as outras manifestações do espírito e com a vida em geral.

Schafer acredita que o ensino de música deva ser construído em conjunto com as outras formas artísticas, artes plásticas, cênicas e dança. Para ele, devemos buscar uma forma de arte múltipla para que o todo faça sentido e se torne significativo. $O$

\footnotetext{
${ }^{2}$ Prescrever - quando um compositor escreve uma música, ele está prescrevendo os sons que deverão ser executados e apreciados posteriormente. Descrever - quando um compositor compõe uma peça musical, ele pode estar descrevendo em sons, elementos ou emoções por ele captadas ou criadas.
} 
aprendizado musical, de forma isolada, deixa uma enorme lacuna no processo de formação do aluno. Para uma educação musical significativa e contextualizada, o princípio do aprendizado coletivo é fundamental. O contato do aluno com o instrumento e a matéria sonora é o mais importante e se torna o primeiro passo a ser dado. Os alunos experimentam apenas os instrumentos disponíveis, pois é assim que normalmente acontece devido à carência de instrumentos musicais que encontramos em muitos locais de trabalho, situação que sempre devemos estar preparados a enfrentar. Mas isto não chega a ser um obstáculo e muitas vezes é um estímulo e um convite à criatividade, pois alunos e professores têm a oportunidade de criar estruturas instrumentais diferentes, com materiais que normalmente não seriam utilizados como instrumentos musicais. $\mathrm{O}$ princípio de aprendizado coletivo articulado com um pensar que valorize as competências trazidas pelos alunos para a partir daí construirmos o conhecimento musical planejado, possibilita a formação de grupos inclusivos, ou seja, verdadeiras orquestras laboratório, onde alunos, professores e público, têm a oportunidade de experimentar novos caminhos sonoros e pedagógicos.

\section{A PESQUISA}

\subsection{O Cenário}

O cenário utilizado como fonte de análise é formado pelo espaço urbano do centro de Niterói e a sala de aula, $\mathrm{n}^{\circ}$ 05, do Conservatório de Música de Niterói, que é uma sala ampla com piano de calda, tv, vídeo cassete, som e lousa. É um espaço de muita diversidade sonora; as salas $n^{\circ}$ 04, 06, 07, 08 e 09 são próximas e não possuem tratamento acústico. O Conservatório fica na esquina das ruas São Pedro e Maestro Felício Toledo, no centro de Niterói, próximas ao Jardim São João e à igreja de São João Batista - Catedral do município de Niterói, onde há uma circulação acentuada de transeuntes e vendedores ambulantes e um trânsito intenso, onde fontes sonoras se misturam com as mais variadas estruturas musicais que são ensinadas no Conservatório.

\subsection{Sujeitos}

Alunos e o professor $^{3}$ da classe de Evolução e História da Música, do curso superior de licenciatura plena em música do Conservatório de Música de Niterói.

\section{2 - O projeto pedagógico analisado}

\footnotetext{
${ }^{3} \mathrm{O}$ professor da classe em questão é também o autor e responsável pela pesquisa.
} 
Foi produzido um $\mathrm{CD}$ de áudio com 9 faixas, composto de recortes de imagens sonoras que compõem a paisagem sonora do ambiente urbano atual de Niterói, juntamente com pequenos trechos usados de forma incidental de música e recortes de obras de Bach (Missa em Si menor) e Haendel (Abertura do Oratório O Messias) compositores expoentes do período Barroco, período este constante do conteúdo programático da disciplina Evolução e História da Música e da qual fazem parte os alunos participantes da pesquisa. Foram utilizados também recortes da música "Deep in Forest", de Heitor Villa-Lobos(VILLA-LOBOS, 2001, faixa 02), e o ambiente de sala de aula onde a pesquisa foi sendo construída, músicas e trilhas compostas pelo pesquisador desta Dissertação, com a colaboração dos participantes da pesquisa que intervieram durante todo o processo com sugestões e ações. As gravações foram feitas in loco, com exceção das trilhas incidentais e da faixa "trilhas na mata", que foram produzidas em estúdio e com auxílio dos computadores Macintosh - Power Book G3 e iMac G3 -, através dos programas de áudio Pro Tools, Digital Performer e Peak e de editoração de partituras Encore e Finale.

A partir deste $\mathrm{CD}$, que passou a ser um instrumento pedagógico e foi sendo transformado a cada encontro, analisamos como os alunos reagiam aos estímulos e descobertas acerca da exposição à paisagem sonora ilustrada no CD.

$\mathrm{Na}$ faixa 1 (sons da cidade), buscamos levar a um "olhar auditivo" mais atento acerca dos sons ambientais do cotidiano onde os sons naturais se misturam aos sons urbanos. Nas faixas 2 (Música harmoniosa - "Trilhas na mata"); 3 (Recortes de músicas de Bach -Missa em Si menor); 4 (Recortes de músicas de Haendel -Abertura do Oratório O Messias); e 5 (Pequeno trecho da música "Deep in Forest" da obra Floresta Amazônica de Heitor Villa-Lobos), consideramos as influências da paisagem da natureza refletidas em imagens sonoras. Na faixa 6 (Música do silêncio), buscamos o contraste do silêncio com os sons do ambiente onde a música está sendo ouvida, transforma cada audição em uma única audição, onde diferentes fontes sonoras que compõem a paisagem do ambiente, se integram, fazendo parte, da música. Na faixa 7 (Música experimental), um tema que nos leva à percepção das influências do ambiente social na produção musical, onde recursos eletrônicos e sons tidos tradicionalmente como ruídos, se misturam à arte musical. Na faixa 8 (Construção coletiva com os alunos), os participantes criam uma composição musical a partir das experiências e do "olhar sonoro" construído através da pesquisa. E na faixa 9 (Música do silêncio 2), 
como sugere Schafer: "toda pesquisa sonora precisa concluir com silêncio", concluímos o CD.

Este relato da pesquisa expressa apenas a análise do primeiro momento do curso, ou seja, as aulas introdutórias e as aulas referente aos estudos realizados durante a audição da Faixa 1 do CD que se constituiu como instrumento didático.

\section{3 - Coleta e análise dos dados 3.3.1 Observação participante}

As nossas observações aconteceram de agosto a novembro de 2005, a partir e durante as aulas da disciplina de Evolução e História da Música do Curso Superior de Licenciatura em Música do Conservatório de Música de Niterói, aulas estas, semanais, com duração de 60 minutos, num total de 17 encontros, em que o pesquisador e professor constituem a mesma pessoa. Buscamos, através da pesquisa participante, uma forma flexível de investigação, na qual, pesquisador e participantes pudessem encontrar respostas ao problema proposto.

Não ficamos surpresos com a certa dose de inércia dos alunos quando proposto que fizessem parte do processo de pesquisa, pois, normalmente quando chegam à universidade estão muito preocupados em adquirir técnicas e modelos prontos para serem implantados e não são estimulados com freqüência a experimentar, ousar, inventar ou improvisar na vida escolar. Pareceu-nos que este comportamento inerte perpassava pela descrença na arte de educar. Os alunos/participantes não acreditavam que o trabalho do educador musical tivesse poderes de ação transformadora, isto talvez, em decorrência da não obrigatoriedade do ensino de música no ensino fundamental e médio que tem o ensino de Artes de maneira integrada compreendendo: Artes Visuais, Teatro, Dança e Música. Esta forma de abordagem das Artes no currículo escolar, contribuiu para uma interpretação, talvez um tanto pessimista, de desvalorização da música e das outras manifestações artísticas frente as suas especificidades.

Os alunos de Música, em nível superior, na maioria das vezes já são músicos, que profissionais ou não, têm ainda marcados pela forma tradicional - no sentido de conservador - do ensino de música, elementos técnicos como preponderantes para um bom desempenho artístico. Assim, estes elementos técnicos e a busca pela formação do virtuose contribui, muitas vezes, para uma abordagem engessada do ensino musical.

Chegando estes alunos à faculdade de licenciatura em música, se deparam com a realidade de que não bastam elementos técnicos e bons instrumentistas para 
desempenhar o lugar de educador musical. Paulo Freire nos diz que: "Como professor devo saber que sem curiosidade que me move, que me inquieta, que me insere na busca, não aprendo nem ensino" (1996, p. 95). Assim, investigar, buscar, decidir, são ações que, muitas vezes, exigem destes alunos maturidade para a desconstrução que se faz necessária no processo de produção do conhecimento e na preparação do docente.

Começamos, então, através das aulas de História da Música e sem perder de foco o programa de curso, a construir reflexões acerca da importância de uma audição cuidadosa e inteligente, e ainda, da função que irão desempenhar na sociedade como professores de música, ajudando a construir esta forma de audição.

Começamos, então, levantar junto aos participantes os conceitos que eles possuíam de som, ruído e poluição sonora. Este foi o nosso ponto de partida por meio de uma construção histórico-social para que pudéssemos, a partir daí, fazer uma interface do conteúdo programático da disciplina com os conceitos que precisávamos levantar. Isto se configurou em grande desafio; primeiro porque os alunos se mostraram surpresos com que relação teriam estes conceitos com o conteúdo específico da nossa disciplina, e depois, porque esperavam uma abordagem expositiva de fatos históricos relevantes ligados à disciplina, e não, que fossem chamados a refletir sobre o contexto histórico a partir de uma abordagem social. Apesar de acreditarmos, e em nossas argumentações sempre enfatizarmos, de que fatos históricos estão sempre aliados contextualmente à realidade social, os alunos esperavam, de forma passiva, a transmissão dos conteúdos relativos à disciplina. O contexto social foi então a forma de abordagem histórica por nós adotada. Assim, começamos também a refletir sobre o conceito de meio ambiente e vinculá-lo à produção artística. O artista e sua obra são influenciados, diretamente, pela sociedade com todos os elementos que a compõe, sendo assim, a relação de troca entre arte e sociedade é constante.

O ambiente fornece elementos para criação musical, que de certa forma, servem de inspiração ou de mote para a produção artística. Schafer (1991, p. 51) destaca aqui uma questão de importante vínculo entre música e ambiente; segundo ele: "a história demonstra que a música está constantemente aumentando de volume". Passo-a-passo, estávamos interpretando dados que possibilitaram à interface entre educação ambiental e educação musical. Conseguimos, então, construir o entendimento sobre a necessidade de estudarmos os conceitos de som, ruído e poluição sonora, para a partir daí, entendermos como estes conceitos influenciaram na produção artístico-musical através do tempo. Este processo levou aproximadamente quatro aulas. 
Num outro encontro estávamos - pesquisador/professor e alunos/participantes concentrados na audição da faixa 01 do $\mathrm{CD}$, bem como, em alguns recortes de peças de Bach e Haendel, que ilustram o pensamento sobre a relação da produção artísticomusical com ambiente social onde buscávamos elementos para a construção dos conceitos de som, ruído e poluição sonora.

Feito um levantamento com a classe sobre o que entendiam por som e ruído, percebemos que, de modo geral, eles associavam o "gosto" às suas definições. Então, percebiam como som eventos sonoros agradáveis, e ruído como eventos sonoros desagradáveis. Isto em si é muito subjetivo. O que agrada alguém pode muito bem desagradar outra pessoa e vice-versa. Eles, ainda, associavam poluição sonora a eventos sonoros emitidos por máquinas e equipamentos usados pelo homem em seu cotidiano. Isto pode ser, também, poluição sonora, porém, não representa uma definição que se sustente frente à complexidade do termo. Trabalhamos, a partir daí, a construção dos conceitos de som, ruído e poluição sonora, tendo como referência o discurso em relação à arte e indústria cultural.

Quando reapresentamos a faixa 1 do $\mathrm{CD}$, que contém sons do cotidiano, os alunos em coro disseram: "Isto é ruído, barulho, poluição sonora". E quando indagados se estes ruídos faziam parte do meio ambiente, eles hesitaram e se dividiram entre sim e não. Os sons de pássaros, folhas ao vento, cigarras e outros sons que também compõem os sons do cotidiano - constantes desta faixa do $\mathrm{CD}$-, além da visão naturalista do conceito de meio ambiente, contribuiram para que os alunos/participantes ficassem divididos. Stravinsky nos diz que os sons naturais são as matérias-primas da música. Colocamos, então, uma questão para reflexão: "Estes sons naturais também compõem o ambiente da mesma forma que os sons dos motores dos automóveis?"

Fez-se necessário neste momento, a construção do conceito de ambiente; concluímos após algumas discussões que, ambiente é muito mais do que elementos naturais e relacionados à fauna e a flora, e ainda, que o ser humano com todas as suas invenções e instrumentos também integram o ambiente. Como nos coloca Reigota, é necessário distinguir atividades e abordagens que tendem a generalizar, e ou, simplificar a visão de ambiente e de educação ambiental.

Há uma tendência em naturalizar o ambiente sem levar em consideração todas as modificações que ele vem sofrendo com o passar dos anos e com o desenvolvimento da sociedade, como se pudéssemos ter uma visão contemplativa dos eventos sociais sem que fizéssemos parte deles. O meio ambiente é um conjunto de coisas constantes em 
nossa sociedade, e nós, como atores principais, devemos ter consciência da interferência que exercemos sobre ele, interferência esta, que pode ser boa ou ruim. A partir daí, colocamos para os participantes, futuros professores de música, o importante lugar que deveriam ocupar frente à necessidade de uma consciência acerca do que chamamos audição inteligente.

\section{CONCLUSÃO}

Esta pesquisa objetivou investigar a produção sonora sócio-ambiental, artística e seus desdobramentos na construção de uma audição inteligente. A música é uma forma de arte que tem como matéria-prima o som - a arte da música também é a arte de ouvir -; a educação é uma via de formação e transformação social; o ambiente nosso habitat. Sendo assim, pareceu-nos natural a união destas três áreas do conhecimento, tão indissociáveis, na aplicabilidade de uma pesquisa social.

Como trabalhamos o universo sonoro, ligado ao ambiente, num processo de educação, escolhemos como sujeitos da pesquisa alunos do Curso Superior de Licenciatura em Música. Os educadores musicais devem possuir instrumentos significativos para investigar o processo de formação destes mesmos educadores. Parafraseando Paulo Freire: "Educar é discernir o ouvir"

O princípio metodológico que adotamos foi o da pesquisa participante, que nos deu a flexibilidade necessária durante todo o processo investigativo. Construímos, então, dos conceitos inerentes ao campo do estudo sonoro e o primeiro deles foi o de paisagem sonora. A partir deste conceito, o entendimento dos conceitos de som, ruído, poluição sonora, música e ambiente, se fizeram necessários para a continuidade do processo de investigação do trabalho empreendido.

Inicialmente nossos alunos/participantes não se mostraram muito interessados; mostram-se ainda, surpresos com a possibilidade de serem chamados à refletir sobre o assunto. A educação musical talvez necessite ampliar seu campo de atuação interagindo com as mais diversas áreas do conhecimento, para que problemas como estes, tão recorrentes em sala de aula, aconteçam com menos freqüência.

$\mathrm{O} \mathrm{CD}$, como instrumento pedagógico, tem sido uma importante ferramenta que pode ser aplicada em diferentes níveis cognitivos e ser adaptada às necessidades de cada grupo. Então, também pouco a pouco, os alunos/participantes foram descobrindo o valor do ouvir e a necessidade de se buscar construir o preparo para o discernimento do que este ouvir resulta. Certa frustração acompanhou-nos durante parte do processo 


\section{ISSN 1983-7011}

quando percebíamos, nestes futuros professores - a quem Schafer atribuiu a responsabilidade pela audição da sociedade -, uma dose de inércia frente ao lugar a ser constituído pelo educador musical. Algumas vezes, uma visão um tanto pessimista em relação à educação se destacava. Mas isto não se constituiu em obstáculo intransponível, pois, integra o processo de descoberta fundamental para o educador; fomos enfrente.

\section{REFERÊNCIAS BIBLIOGRÁFICAS}

FREIRE, Paulo. Pedagogia da autonomia. São Paulo: Editora Paz e Terra, 1996.

NEVES, Estelal; TOSTES, André. Meio Ambiente a lei em suas mãos. Petrópolis: Editora Vozes, 1998.

SCHAFER, R. Murray. A Afinação do Mundo. São Paulo: Fundação Editora da

UNESP, 2001.

UNESP, 1991.

. O Ouvido Pensante. São Paulo: Fundação Editora da

REIGOTA, Marcos. O que é Educação Ambiental. São Paulo: Ed. Brasiliense, 2001.

\section{REFERÊNCIAS DISCOGRÁFICAS}

BACH, Johann Sebastian. Grande Missa em Si menor - BWV 232 (1). 1 CD (50.8 min.).

HAENDEL, George Frederic. Messias (1). Barcelona: Ediciones Altaya S.A., 1996, $1 C D$ (1 h. $10 \mathrm{~min}$ ).

SCHOENBERG, Arnold. Pierrot Lunaire - melodrama op. 21. Rio de Janeiro: Musiosom - Emp. Musicais Ltda, 1999, 1 CD (31.7 min.).

VILLA-LOBOS, Heitor. Forest of the amazon. Califórnia: Delos International, inc., 2001, 1 CD (74 min.). 